\title{
The Effect of Resveratrol on Aortic Function in Patients with Marfan Syndrome - Rationale and Design of the Resvcue Marfan Trial.
}

\section{Mitzi M van Andel}

Amsterdam Universitair Medische Centra https://orcid.org/0000-0002-4629-568X

Pim van Ooij

Amsterdam UMC - Locatie AMC: Amsterdam UMC Locatie AMC

Arthur JHA Scholte

Leids Universitair Medisch Centrum

Maarten $P$ van den Berg

Universitair Medisch Centrum Groningen

Michael G Dickinson

Universitair Medisch Centrum Groningen

\section{Roland RJ van Kimmenade}

Universitair Medisch Centrum Sint Radboud: Radboudumc

Floor Bennebroek Evertsz'

Amsterdam UMC - Locatie AMC: Amsterdam UMC Locatie AMC

\section{Aeilko $\mathrm{H}$ Zwinderman}

Amsterdam UMC - Locatie AMC: Amsterdam UMC Locatie AMC

Barbara JM Mulder

Amsterdam UMC - Locatie AMC: Amsterdam UMC Locatie AMC

Maarten Groenink

Amsterdam UMC - Locatie AMC: Amsterdam UMC Locatie AMC

Vivian de Waard ( $\square$ v.dewaard@amsterdamumc.nl)

Amsterdam UMC - Locatie AMC: Amsterdam UMC Locatie AMC

\section{Study protocol}

Keywords: Marfan syndrome, aneurysm, aorta, Resveratrol

Posted Date: June 7th, 2021

DOI: https://doi.org/10.21203/rs.3.rs-434876/v1 
License: (c) (i) This work is licensed under a Creative Commons Attribution 4.0 International License. Read Full License 


\section{Abstract}

\section{Background}

Marfan syndrome (MFS) is a connective tissue disorder characterized by mutations in the fibrillin-1 (FBN1) gene. The most important manifestation is progressive enlargement of the aorta, ultimately leading to aortic dissection or rupture. Present day pharmacological treatment is based on drugs that decrease repetitive stress on the aorta and improve elastic properties and transport function of the aorta. Unfortunately, this is not sufficient for most patients and surgical resection and reconstruction of the enlarged part of the aorta is still necessary. We have shown earlier that the food supplement Resveratrol inhibits aortic growth and promotes aortic repair in a murine MFS model. Resveratrol is a natural polyphenol commonly found in the skin of berries and in nuts. Here, we hypothesize that Resveratrol treatment will also be protective against aortic dilatation and functional deterioration in humans with MFS.

\section{Methods/Design}

The RESVcue Marfan study is an investigator-initiated, prospective, pre-post observational, multicenter trial. Four specialized academic centers in the Netherlands will recruit 100 patients with genetically confirmed MFS. Patients will use Resveratrol for one year, on top of their ongoing medicinal regime. The primary endpoints consist of the following two main parameters; 1 ) aortic aneurysm expansion rate and 2) improvement of aortic functional indices. All indices will be measured before and after treatment by echocardiography and (4D flow) MRI. The 4D flow MRI allows for analysis of blood flow patterns and quantification of stresses on the aortic wall, distensibility and pulse wave velocity. Blood and skin samples will be taken to assess the effect of Resveratrol on potential biomarkers associated with Resveratrol metabolism and changes in the primary endpoints. Three psychological tests (The Well-being questionnaire (SF-12), the Hospital Depression and Anxiety Scales (HADS) questionnaire and the Checklist Individual Strength (CIS)) will be taken by the MFS patients to assess the effect of Resveratrol on their well-being.

\section{Discussion}

The RESVcue Marfan trial may provide sufficient data on beneficial effects of Resveratrol on aortic aneurysm expansion rate, aortic functional properties, and biomarkers in patients with MFS to justify a future randomized trial in a larger cohort for a longer study period.

\section{Trial registration}

NL66127.018.18, approved on 24 September 2018. https://www.toetsingonline.nl/ Resveratrol as potential aortic growth inhibitor in patients with Marfan syndrome.

\section{Background}


Marfan syndrome (MFS) is an autosomal dominant inherited disorder of connective tissue, characterized by mutations in the fibrillin-1 (FBN1) gene. Patients with MFS suffer from an increased risk of cardiovascular disease, in particular: aortic root aneurysm formation, aortic aneurysm formation beyond the aortic root and aortic dissection or rupture. This leads to enhanced morbidity and a reduced life expectancy if left untreated $(1,2)$.

Pharmacological treatment is based on blood pressure lowering drugs, using mostly $\beta$-blockers or angiotensin II receptor type 1 blockers (ARBs), like losartan. Although these drugs offer some benefit in reduction of aortic aneurysm expansion rate and in the occurrence of aortic dissection (3), they do probably not sufficiently target the underlying cause of the progressive aortic degradation. While the past two decades have uncovered different mechanisms involved in aortic disease in MFS, we still do not exactly know how FBN1 gene defects result in aortic pathology. The abundance in FBN1 mutations (> 3000 variants in the Universal Mutation Database (4)) in part explains the heterogeneity of aortic manifestations seen in MFS, yet it does not explain the diversity within MFS family members with the same mutation. This is probably caused by variation in genetic modifiers. Rather than to focus on the differences, it may be of interest to focus on what patients with MFS have in common.

The general concept in MFS is that the extracellular matrix (ECM) network in the aorta is defective, resulting in excessive ECM remodeling by the aortic smooth muscle cells (SMCs), which undergo phenotypical changes and will eventually be subjected to cell death. Moreover, the inner cell-lining of the aorta, the endothelial cells that are in contact with the circulation, may also become dysfunctional in MFS (5), which will lead to disturbed communication between endothelial and SMCs. Interestingly, impairment of flow-mediated dilation (as a readout of endothelial dysfunction) correlates with increased aortic root diameters in MFS patients (5). Since we have previously shown that Resveratrol could enhance SMC regeneration in a mouse model of MFS, in part by improving endothelial function (6), we hereby postulate that Resveratrol may be a suitable therapeutic to use in human patients with MFS.

Resveratrol is a stilbenoid (3,5, 4'-trihydroxystilbene) commonly found in the skin of berries, in nuts and produced upon injury by plants $(7,8)$. It has become a popular dietary supplement since it was shown to reduce cellular ageing processes in non-human studies (9). There are several mechanisms by which Resveratrol could exert a beneficial effect in MFS (10). First, Resveratrol has been shown to improve mitochondrial function (energy metabolism) in human muscle (11-13), which may also apply to the SMCs in the aorta, potentially promoting SMC survival. Impaired mitochondrial respiration has been shown in MFS and Loeys-Dietz patient fibroblasts (14), which thus seems a common pathological feature that may be targeted by Resveratrol. Secondly, Resveratrol has been described to restore endothelial function in arteriosclerosis, kidney failure and obese patients (15-17). The effect of Resveratrol on endothelial function is mainly due to increased nitric oxide (NO) homeostasis and thereby reducing oxidative stress, also in the SMCs (18). The importance of dysbalanced NO in MFS has been elegantly shown in MFS mice by rescue of aortic dilation by the NO synthase inhibitor N(G)-nitro-Larginine methyl ester (L-NAME) (19). L-NAME is not considered safe to use in human studies because it also inhibits neuronal NO synthase, thus is not an option for therapy in MFS. 
The primary aim of the RESVcue Marfan trial is to evaluate potential beneficial effects of the food supplement Resveratrol on aortic degenerative disease in patients with MFS. More in detail we will investigate this effect on different levels; 1 ) morphologically: on aneurysm expansion rate as measured by echocardiography and magnetic resonance imaging (MRI), 2) functionally: on aortic elastic properties and wall shear stress as measured by MRI and 3) biochemically: disease biomarkers in plasma and in skin biopsies on protein and mRNA level, respectively.

\section{Methods}

\section{Study oversight}

The RESVcue Marfan study is a pre-post observational, multicenter, clinical trial performed in four Dutch university hospitals with a specialized multidisciplinary Marfan screening clinic. The RESVcue Marfan trial will collect data on effects of Resveratrol on aortic diameters and aneurysm expansion rate, aortic functional properties, and biomarkers in patients with MFS to justify a future randomized trial in a larger cohort for a longer study period. The Amsterdam UMC will be responsible for data collection and monitoring. The study authors are responsible for data analysis and interpretation. Any serious adverse events (fatal, life-threating, disabling or resulting in hospitalization or prolongation of hospitalization) will be reported to the accredited local ethics board, without undue delay after obtaining knowledge of the events.

The local ethics board, as well as all the institutional review boards of the local centers approved the study. Written informed consent will be obtained from all participants prior to the first outpatient clinic visit and start of Resveratrol use (see supplementary material). In all cases it is the responsibility of the research fellow to obtain written informed consent.

\section{Eligibility criteria}

In this study, a total of 100 patients with MFS will be enrolled for treatment with Resveratrol $500 \mathrm{mg} /$ day. The study design is displayed in Fig. 1. In detail, all patients with confirmed MFS (following the revised Ghent criteria and with a known FBN1 mutation) are assessed for study eligibility. Patients will be identified by all four Dutch university hospitals with a specialized multidisciplinary Marfan screening clinic (Amsterdam UMC - Academic Medical Center, Amsterdam; Radboud University Medical Center, Nijmegen; University Medical Center Groningen, Groningen; Leiden University Medical Center, Leiden) and by using the CONgenital CORvita (CONCOR) Dutch national registry for adult congenital heart disease (20).

Patients are eligible for study participation if the following criteria are met: (i) patients aged between 18 and 50 years, (ii) have a maximum of one aortic prosthesis restricted to the aortic root, (iii) have a stable blood pressure, (iv) have at least two measurements by echocardiography and one measurement by MRI or computed tomography (CT) of the entire aorta available prior to inclusion. Patients will be excluded when they (i) have an aortic root diameter $>50 \mathrm{~mm}$, (ii) have a history of aortic dissection, (iii) have more 
than one aortic prosthesis, (iv) have had aortic surgery in the last 6 months prior to inclusion or (v) are likely to have aortic surgery within the first 6 months of inclusion. Moreover, patients are considered ineligible if they (vi) are known with mental retardation or (vii) are pregnant or have the intention to become pregnant within the study length.

\section{Intervention with Resveratrol}

Description and justification of route of administration and dosage. Patients will start with Resveratrol 500 mg daily, produced by European Health \& Fitness Group (EHF Group) with Veri-te Resveratrol, isolated and purified by Evolva. Evolva is represented in the Netherlands by Lithos Ingredients. In 18 (non-cancer related) human Resveratrol studies published since 2015, 24 dosages were used, of which the median dosage was $500 \mathrm{mg} /$ day (orally) and the median time of treatment 3 months with no side effects. Therefore, we will use $500 \mathrm{mg} /$ day (for one year). Trans-resveratrol is a substance of low oral toxicity, which is supported by human clinical studies using dosages up to $5 \mathrm{~g}$ /day for 28 days (21).

Summary of known and potential risks and benefits. The use of other cardiovascular medication will be recorded. No adjustments will be made to the already existing, patient-specific, treatment. No harmful effects were reported when using concentrations of Resveratrol $500 \mathrm{mg} /$ day in human studies published since 2015. In the meta-analysis of 21 studies in obese patients a small reduction in blood pressure was observed upon Resveratrol treatment $(-2.26 \mathrm{mmHg} ; 95 \% \mathrm{Cl},-4.82$ to $-0.49 ; \mathrm{P}=0.02)$ (22). When side effects, such as dizziness or syncope occur, the Resveratrol dosage will be reduced. Based on the COMPARE cohort(23), we do not expect to include patients suffering from Diabetes Mellitus, hypertension or dyslipidemia. May this be the case, extra attention will be paid to any interaction with used medication.

Therapy adherence. Before starting treatment with Resveratrol, the patients will be sufficiently informed on the hypothetical working mechanism of Resveratrol, to enhance adherence to treatment. In addition, the reasoning for the given dosage will be explained. During the quarterly follow-up by telephone, specific questions will be asked, which can inform the investigators (in)directly about the adherence to therapy.

\section{Outcome definitions}

The primary outcome is to evaluate beneficial effects of the food supplement Resveratrol on aortic degenerative disease, with two main parameters: 1) aortic diameters (aneurysm expansion rate) and 2) improvement of aortic functional indices. All indices (described more in detail in 'measuring the effect of Resveratrol') will be measured before and after treatment by echocardiography and (4D flow) MRI. The $4 \mathrm{D}$ flow MRI allows for analysis of blood flow patterns and quantification of stresses on the aortic wall, distensibility and pulse wave velocity.

Secondary endpoints include measured changes upon Resveratrol use in: 1) cardiac parameters and abnormalities, 2) potential disease biomarkers in plasma or skin samples, and 3) patient wellbeing. In addition, we will evaluate (i) an association between patient plasma asprosin (FBN1 gene related hormone) levels with body fat mass and other patient characteristics, (ii) male and female differences in disease progression, (iii) Resveratrol response in patients with a native aorta compared to patients who 
have had aortic root replacement surgery, and (iv) patients with a haploinsufficient (HI) FBN1 mutation compared to patients with a dominant negative (DN) FBN1 mutation. Clinical geneticists determine the HI or DN status of the FBN1 mutation.

\section{Participants timeline}

Time schedule of enrolment, intervention, assessments, and visits for participants are schematically displayed in Fig. 2.

\section{Sample size}

Measured by MRI, the average annual growth of the aortic root in patients with MFS is approximately $0.35 \mathrm{~mm} /$ year with a standard deviation of 0.49 (19). With 100 patients the width of the $95 \%$ confidence interval of the average annual growth rate with Resveratrol treatment is therefore approximately 0.2 $\left(4^{\star} 0.49 / 10\right)$, which we judge to be sufficient to be used as a basis for decision making for a randomized phase IIb or Phase III study. With 100 patients there will be $80 \%$ power to find a statistically significant Cohen's effect size of about 0.3 or more. Such a large effect has not been observed so far with pharmacological interventions in Marfan patients, but a Cohen's effect size of 0.3 is considered to be moderate.

\section{Measuring the effect of Resveratrol}

Physical examination. Careful physical examination is performed at each visit, especially focusing on (decrease in) blood pressure. If patient experience side effects, blood pressure will be measured more frequently.

Imaging. Prior to inclusion, all patients included in the study have at least two measurements by echocardiography and one measurement by MRI or CT of the aortic root diameter available. In the study, echocardiography and MRI will be performed in addition before and after one year Resveratrol use. The imaging data prior to the study together with the data of the inclusion scan are used to determine the aortic growth rate in the aortic root and throughout the entire aorta trajectory at several landmarks in the thoracic aorta before Resveratrol use. The imaging data obtained during the study (2 scans; at inclusion and at termination of the study) will reveal if there is a reduced aortic growth rate upon Resveratrol use.

Echocardiographic analyses. Transthoracic echocardiography will be performed with a Vivid 7 (GE, Vingmed Ultrasound, Horton, Norway) ultrasound system by experienced ultrasound technicians. Aortic root diameters will be measured in end-diastole at the level of the sinus of Valsalva, by using the leading edge to leading edge technique in parasternal long axis, consistent with current American Society of Echocardiography guidelines. In general, patients have more measurements of the aortic diameters with echocardiography than with MRI throughout their life, therefore measurement by echocardiography will provide us with useful information on the aortic dilation rate. Furthermore, LV function and the presence/severity of valvular disease will be assessed by echocardiography. 
MRI analyses. Study subjects will be examined in supine position in a 3Tesla MR scanner using a high power gradient system (Ingenia, Philips, Best, The Netherlands). All MRI scans will be performed at one center (Amsterdam UMC - Amsterdam Medical Center). First localization of the aorta by balanced SSFP sequences will take place. The entire aorta will then be visualized using a Dixon 3D sequence with specific read-outs for water, fat, in phase and out phase MR signals and with an isotropic resolution of $1 \times 1 \times 1 \mathrm{~mm}$. This sequence will be applied both in systolic and diastolic time-frames for analysis of aortic strain patterns.

A 4D-Flow phase contrast sequence will be applied to the entire thoracic aorta. This sequence will yield time resolved images of 3D aortic luminal velocities with a temporal resolution of approximately $30 \mathrm{~ms}$ and an isotropic spatial resolution of $2.5 \times 2.5 \times 2.5 \mathrm{~mm}$ according to the guidelines (24).

4D-Flow MRI has been used to study helicity and vorticity of flow patterns and how those relate to aortic dilation in MFS (25). Compared to controls, MFS patients revealed different flow patterns due to dilatation or tortuosity of the aorta $(26,27)$. Thereby, it has been shown that the systolic wall shear stress in patients with MFS was significantly lower in the proximal inner descending aorta, compared to controls, which decreased further during ageing (28). 4D MRI-based aortic pressure mapping showed that pressure gradients at mid systole significantly correlated with aortic diameter in the proximal ascending and proximal descending aorta in MFS patients (29). Aortic elasticity can be deduced from a combination of pulse pressure (measured by a sphygmomanometer cuff during the MRI scan) and 4D flow MRI data to calculate pulse wave velocities and aortic distensibility. Resveratrol could potentially have a beneficial effect on pulse wave velocities and aortic distensibility by enhancing endothelial function and SMC regeneration, and thereby improving ECM remodelling. Our study will show if Resveratrol influences aortic characteristics on these different levels.

Blood samples. Venous blood $(20 \mathrm{~mL})$ will be collected of every patient included in the study at baseline and after one year of Resveratrol use. In the EDTA plasma samples we will measure Resveratrol metabolites as readout of Resveratrol use, and potential biomarkers correlated to aortic disease.

For thoracic aortic aneurysm disease a small number of biomarker studies have been performed previously, which may be validated in the current Resveratrol cohort. As plasma biomarkers for aortic disease, proteins representing damaged ECM or SMC death may be measured. In the aorta, fibrillin-1 forms elastin fibers together with elastin protein. Since fibrillin-1 in the MFS cohort is the defective ECM protein, fibrillin-1 fragments can be measured as readout of aortic damage. In thoracic aneurysm patients, increased fibrillin-1 fragments in the circulation are associated with aortic dissection (30). Along those lines, elastin fragments (desmosin) may be used as biomarker, since plasma desmosin showed a strong correlation with aortic diameter and aortic events in abdominal aortic aneurysm patients (31). Elastin fragments could also discriminate thoracic aorta dissection patients (including MFS) from other cardiovascular patients and controls (32). Interestingly, microfibrillar-associated protein 4 (MFAP4) is involved in fibrillin-1 and elastin fiber formation and repair in all elastic tissues (33), and enhanced in the MFS aorta $(34,35)$. We have recently shown that patients with MFS in the highest tertile of serum MFAP4, 
representing active fiber repair, were at risk for aortic dissection during 7 years follow up (35).

Transforming growth factor beta (TGF $\beta$ ) is considered an important factor that is dysregulated in MFS. Normally, TGF $\beta$ is a wound healing factor, which regulates ECM production and remodeling. Yet, in MFS the enhanced TGF $\beta$ causes a fibrotic aortic vessel wall and a change in SMC phenotype (36). We have shown that plasma TGF $\beta$ associates with aortic root growth in MFS (37), thus TGF $\beta$ may be used to monitor aggressive aneurysm dilatation. As mentioned previously, aortic SMCs change phenotype in MFS and upon enhanced aortic disease they die. One of the characteristic structural proteins that is enhanced in MFS SMC is the SMC marker smooth muscle specific alpha actin (ACTA2)(36). We anticipate that enhanced plasma ACTA2 may function as a marker of increased SMC death in MFS and will associate with severity of aortic disease.

Skin fat measurements and skin biopsy. Skin fat measurements are taken because a subgroup of patients with MFS has typical marfanoid features such as being tall and slender, having long bones and reduced body fat mass whereas other patients with MFS do not have such features. We will measure subcutaneous fat mass for indications of mild lipodystrophy. Lipodystrophy syndrome has recently been ascribed to mutations in the terminal part of the FBN1 gene, in the peptide hormone region coding for Asprosin (38). Asprosin is cleaved from the rest of fibrillin-1 and has a metabolic function to regulate glucose release from the liver in times of fasting (39). Lack of Asprosin causes reduced adipogenesis and excessive fat utilization as energy source due to reduced glucose availability. We anticipate that patients with a FBN1 mutation leading to decreased fibrillin-1 production (haploinsufficiëncy) may also have reduced Asprosin, thus reduced fat mass. The skin fat measurements will be correlated to plasma Asprosin levels and FBN1 mutation type to unravel if Asprosin is a biomarker for the HI subtype of MFS. The effect of Resveratrol on skin fat mass and the association of Asprosin plasma levels to aortic features will be analyzed as well. By measuring the thickness of skin folds, one can determine the amount of subcutaneous adipose tissue. Measurements are taken with the patient in standing position, on the right side of the body. The patient must relax the muscle group that is being assessed. The skin fold measurements are then applied on triceps, biceps, subscapular and suprailiac skin. There are several tables available to translate the result of the measurement of the skin folds into body fat percentages. The table of Durnin and Womersley is most commonly used and will also be applied in this study (40).

Skin is also a connective tissue containing fibrillin-1 and elastin fibers. Therefore, the patients with MFS will undergo a punch skin biopsy ( $3 \mathrm{~mm}$ in diameter) from the front side of the upper leg at baseline and after one year of Resveratrol use. Lidocaine ( $2 \%$ ) will be used as local anesthesia. Skin samples will be useful as surrogate for aortic tissue, to provide further understanding of the pathophysiology of MFS by studying the mRNA expression profile before and after Resveratrol use in relation to aortic features. Results will be used to build prediction models of the Resveratrol therapy response and to identify genes which may influence aortic disease. In that light, in skin samples of MFS patients within the COMPARE cohort (23) we found that mRNA expression of transcription factor krüppel-like factor 4 (KLF4) was one of the top genes associated with aortic growth (Fig. 3). KLF4 is considered a key regulator in SMC phenotype in aneurysm disease (41) and recently shown in the most widely used MFS mouse model (42). In human MFS tissue, a similar phenotypical SMC change was seen when compared to the MFS mice, 
suggesting a similar regulator (42). Moreover, inhibition of the enhanced KLF4 expression in human MFS SMC promoted SMC survival (43). Therefore, mRNA expression of KLF4 in skin may be a potential biomarker to assess aortic dilatation rate in MFS, and upon treatment.

Questionnaires. MFS has various implications that can impact quality of life. Psychosocial issues such as a negative impact on an individual's formative years, reproductive decision-making, work participation and general feeling of wellbeing are not uncommon. In order to obtain insight in the psychosocial status of our patients, all patients will fill out three questionnaires before and after one year of Resveratrol use; Well-being questionnaire (SF-12), Hospital Depression and Anxiety Scales (HADS) and Checklist Individual Strength (CIS). The effect of Resveratrol on psychosocial status will be determined.

- Generic health-related quality of life will be assessed with the 12-item Short Form Survey (SF-12), a shortened version of the MOS SF-36 (44). The SF-12 measures eight health aspects, namely physical functioning, role limitations due to physical health problems, bodily pain, general health, vitality (energy/fatigue), social functioning, role limitations due to emotional problems, and mental health (psychological distress and psychological well-being). Its items are combined to form the Physical Component Summary (PCS) and the Mental Component Summary (MCS). These summary scales based on the SF-12 correlate very highly with the SF-36 versions(45).

- Anxiety and depressive symptomatology will be assessed with the standardized and validated Hospital Anxiety and Depression Scale (HADS) $(46,47)$. It is a measure specifically designed for patients with somatic illness, consisting of an anxiety and a depression subscale, both containing seven items. A score $\geq 8$ on either subscale indicates a possible psychiatric-, anxiety-and/or depressive disorder and a score $\geq 11$ indicates a probable psychiatric disorder in the same category. HADS is a questionnaire that was found to perform well in assessing the symptom severity of anxiety disorders and depression in both somatic, psychiatric and primary care patients(48).

- The Checklist Individual Strength (CIS) questionnaire measures fatigue and behavioral aspects related to this in a subjective manner and it consists of 20 items(49). The questions are divided into four subscales: fatigue severity, concentration problems, reduced motivation and activity. We will be using the subscale fatique severity. This subscale consists of eight items assessing fatique severity over the past two weeks. Scores range between eight (no fatique) and 56 (severe fatique). The cutoff score for severe fatique is $35(50)$. It is a valid and reliable tool for the assessment of fatigue, with a validated cut-off score for severe fatigue that can be used in clinical practice (51).

\section{Follow up}

After the baseline clinical evaluation, including all diagnostic tests mentioned above, follow-up by telephone will be performed the following 3, 6 and 9 months. Patients will be contacted, to register any complaints, concerns or side effects. After one year of Resveratrol treatment, all patients will return to the outpatient clinic. The above-mentioned examinations and measurements will be repeated. Clinical followup will be performed earlier if patients experience any side effects. 


\section{Discussion}

MFS is a heritable condition in which progressive enlargement of the aortic root and thoracic aorta, with potential rupture is the most severe manifestation. Present day, the only pharmacological treatment option consists of $\beta$-blockers or ARBs. Unfortunately, despite drug treatment, patients often still need surgical intervention to replace the enlarged part of the aorta. The RESVcue Marfan study, which focuses on the effect of Resveratrol on the expansion rate of thoracic aortic aneurysms and functional aortic parameters, could provide a new pharmacological treatment option to reduce disease severity. If a beneficial effect on aortic growth or aortic function is shown after one year of Resveratrol use, a randomized study may be initiated in a larger cohort for a longer duration time.

\section{Trial status}

The RESVcue Marfan trial is currently actively recruiting patients. The first patient was enrolled in March 2019 , and recruitment is ongoing. At the moment 60 patients have been included. Completion of patient recruitment is expected for January 2021.

\section{Abbreviations}

DN Dominant-negative

ECM Extracellular matrix

FBN1 Fibrillin-1

HI Haploinsufficient

MFAP4 Microfibrillar-associated protein 4

MFS Marfan syndrome

MRI Magnetic resonance imaging

SMC Smooth muscle cell

TGF $\beta \quad$ Transforming growth factor $\beta$

\section{Declarations}

\section{Funding}

The RESVcue Marfan study is funded by private funding of a Marfan family via the AMC Foundation and the Horstingstuit Foundation.

\section{Handling and storage of data and documents}

The investigator ensures that patient anonymity is maintained, according to the General Data Protection Regulation (GDPR). On CRF's and other documents, patients are not identified by their names or dates of births but by randomly as-signed identification codes. The investigator keeps a separate log of patient's codes, names and addresses, where only the research fellow will have excess to. The investigator 
maintains all documents in strict confidence. Data will be collected in Castor EDC, a platform that offers a solution for capturing medical research data in clinical trials.

\section{Availability of data and materials}

The datasets generated and analyzed during the current study will become available from the corresponding author on reasonable non-commercial request.

\section{Authors' contribution}

VW and MG proposed and initiated RESVcue Marfan. MMA, AHZ, BJMM, MG and VW defined the research strategy. AHZ provided statistical expertise. AJAHS, MPB, MD, RK, FBE, PO are our collaborators. MMA, MG and VW drafted the manuscript. AHZ and BJMM revised the manuscript for important intellectual content. All authors read and approved the final manuscript.

\section{Ethics approval and consent to participate}

This study was approved by the local ethics board of the Amsterdam UMC - AMC (Amsterdam, the Netherlands). All the institutional review boards of the local centers approved participation in the study. Written, informed consent to participate will be obtained from all participants.

\section{Consent for publication}

Not applicable.

\section{Competing interests}

The authors declare that they have no competing interests.

\section{References}

1. Murdoch JL, Walker BA, Halpern BL, Kuzma JW, McKusick VA. Life expectancy and causes of death in the Marfan syndrome. The New England journal of medicine. 1972;286(15):804-8.

2. Silverman DI, Burton KJ, Gray J, Bosner MS, Kouchoukos NT, Roman MJ, Boxer M, Devereux RB, Tsipouras P. Life expectancy in the Marfan syndrome. The American journal of cardiology. 1995;75(2):157-60.

3. van Andel MM, Indrakusuma $R$, Jalalzadeh $H$, Balm R, Timmermans J, Scholte AJ, van den Berg MP, Zwinderman AH, Mulder BJM, de Waard V, Groenink M. Long-term clinical outcomes of losartan in patients with Marfan syndrome: follow-up of the multicentre randomized controlled COMPARE trial. European heart journal. 2020.

4. Collod-Beroud G, Le Bourdelles S, Ades L, Ala-Kokko L, Booms P, Boxer M, Child A, Comeglio P, De Paepe A, Hyland JC, Holman K, Kaitila I, Loeys B, Matyas G, Nuytinck L, Peltonen L, Rantamaki T, 
Robinson P, Steinmann B, Junien C, Beroud C, Boileau C. Update of the UMD-FBN1 mutation database and creation of an FBN1 polymorphism database. Human mutation. 2003;22(3):199-208.

5. Takata M, Amiya E, Watanabe M, Omori K, Imai Y, Fujita D, Nishimura H, Kato M, Morota T, Nawata K, Ozeki A, Watanabe A, Kawarasaki S, Hosoya Y, Nakao T, Maemura K, Nagai R, Hirata Y, Komuro I. Impairment of flow-mediated dilation correlates with aortic dilation in patients with Marfan syndrome. Heart and vessels. 2014;29(4):478-85.

6. Hibender S, Franken R, van Roomen C, Ter Braake A, van der Made I, Schermer EE, Gunst Q, van den Hoff MJ, Lutgens E, Pinto YM, Groenink M, Zwinderman AH, Mulder BJ, de Vries CJ, de Waard V. Resveratrol Inhibits Aortic Root Dilatation in the Fbn1C1039G/+ Marfan Mouse Model. Arteriosclerosis, thrombosis, and vascular biology. 2016;36(8):1618-26.

7. Burns J, Yokota T, Ashihara H, Lean ME, Crozier A. Plant foods and herbal sources of resveratrol. Journal of agricultural and food chemistry. 2002;50(11):3337-40.

8. Soleas GJ, Diamandis EP, Goldberg DM. Resveratrol: a molecule whose time has come? And gone? Clin Biochem. 1997;30(2):91-113.

9. Li YR, Li S, Lin CC. Effect of resveratrol and pterostilbene on aging and longevity. BioFactors (Oxford, England). 2018;44(1):69-82.

10. van Andel MM, Groenink M, Zwinderman AH, Mulder BJM, de Waard V. The Potential Beneficial Effects of Resveratrol on Cardiovascular Complications in Marfan Syndrome Patients(-)Insights from Rodent-Based Animal Studies. International journal of molecular sciences. 2019;20(5).

11. Alway SE, McCrory JL, Kearcher K, Vickers A, Frear B, Gilleland DL, Bonner DE, Thomas JM, Donley DA, Lively MW, Mohamed JS. Resveratrol Enhances Exercise-Induced Cellular and Functional Adaptations of Skeletal Muscle in Older Men and Women. The journals of gerontology Series A, Biological sciences and medical sciences. 2017;72(12):1595-606.

12. Pollack RM, Barzilai N, Anghel V, Kulkarni AS, Golden A, O'Broin P, Sinclair DA, Bonkowski MS, Coleville AJ, Powell D, Kim S, Moaddel R, Stein D, Zhang K, Hawkins M, Crandall JP. Resveratrol Improves Vascular Function and Mitochondrial Number but Not Glucose Metabolism in Older Adults. The journals of gerontology Series A, Biological sciences and medical sciences. 2017;72(12):1703-9.

13. Timmers S, de Ligt M, Phielix E, van de Weijer T, Hansen J, Moonen-Kornips E, Schaart G, Kunz I, Hesselink MK, Schrauwen-Hinderling VB, Schrauwen P. Resveratrol as Add-on Therapy in Subjects With Well-Controlled Type 2 Diabetes: A Randomized Controlled Trial. Diabetes care. 2016;39(12):2211-7.

14. van der Pluijm I, Burger J, van Heijningen PM, A IJ, van Vliet N, Milanese C, Schoonderwoerd K, Sluiter W, Ringuette LJ, Dekkers DHW, Que I, Kaijzel EL, Te Riet L, MacFarlane EG, Das D, van der Linden R, Vermeij M, Demmers JA, Mastroberardino PG, Davis EC, Yanagisawa H, Dietz HC, Kanaar R, Essers J. Decreased mitochondrial respiration in aneurysmal aortas of Fibulin-4 mutant mice is linked to PGC1A regulation. Cardiovascular research. 2018;114(13):1776-93.

15. Agarwal B, Campen MJ, Channell MM, Wherry SJ, Varamini B, Davis JG, Baur JA, Smoliga JM. Resveratrol for primary prevention of atherosclerosis: clinical trial evidence for improved gene 
expression in vascular endothelium. International journal of cardiology. 2013;166(1):246-8.

16. Lin CT, Sun XY, Lin AX. Supplementation with high-dose trans-resveratrol improves ultrafiltration in peritoneal dialysis patients: a prospective, randomized, double-blind study. Renal failure. 2016;38(2):214-21.

17. Wong RH, Berry NM, Coates AM, Buckley JD, Bryan J, Kunz I, Howe PR. Chronic resveratrol consumption improves brachial flow-mediated dilatation in healthy obese adults. Journal of hypertension. 2013;31(9):1819-27.

18. Li H, Xia N, Hasselwander S, Daiber A. Resveratrol and Vascular Function. International journal of molecular sciences. 2019;20(9).

19. Oller J, Mendez-Barbero N, Ruiz EJ, Villahoz S, Renard M, Canelas LI, Briones AM, Alberca R, LozanoVidal N, Hurle MA, Milewicz D, Evangelista A, Salaices M, Nistal JF, Jimenez-Borreguero LJ, De Backer $\mathrm{J}$, Campanero MR, Redondo JM. Nitric oxide mediates aortic disease in mice deficient in the metalloprotease Adamts 1 and in a mouse model of Marfan syndrome. Nature medicine. 2017;23(2):200-12.

20. van der Velde ET, Vriend JW, Mannens MM, Uiterwaal CS, Brand R, Mulder BJ. CONCOR, an initiative towards a national registry and DNA-bank of patients with congenital heart disease in the Netherlands: rationale, design, and first results. European journal of epidemiology. 2005;20(6):54957.

21. Edwards JA, Beck M, Riegger C, Bausch J. Safety of resveratrol with examples for high purity, transresveratrol, resVida(®). Annals of the New York Academy of Sciences. 2011;1215:131-7.

22. Huang H, Chen G, Liao D, Zhu Y, Pu R, Xue X. The effects of resveratrol intervention on risk markers of cardiovascular health in overweight and obese subjects: a pooled analysis of randomized controlled trials. Obes Rev. 2016;17(12):1329-40.

23. Groenink M, den Hartog AW, Franken R, Radonic T, de Waard V, Timmermans J, Scholte AJ, van den Berg MP, Spijkerboer AM, Marquering HA, Zwinderman AH, Mulder BJ. Losartan reduces aortic dilatation rate in adults with Marfan syndrome: a randomized controlled trial. European heart journal. 2013;34(45):3491-500.

24. Dyverfeldt P, Bissell M, Barker AJ, Bolger AF, Carlhäll CJ, Ebbers T, Francios CJ, Frydrychowicz A, Geiger J, Giese D, Hope MD, Kilner PJ, Kozerke S, Myerson S, Neubauer S, Wieben O, MarkI M. 4D flow cardiovascular magnetic resonance consensus statement. Journal of cardiovascular magnetic resonance : official journal of the Society for Cardiovascular Magnetic Resonance. 2015;17(1):72.

25. Farag ES, van Ooij P, Planken RN, Dukker KCP, de Heer F, Bouma BJ, Robbers-Visser D, Groenink M, Nederveen AJ, de Mol B, Kluin J, Boekholdt SM. Aortic valve stenosis and aortic diameters determine the extent of increased wall shear stress in bicuspid aortic valve disease. Journal of magnetic resonance imaging : JMRI. 2018;48(2):522-30.

26. Geiger J, Markl M, Herzer L, Hirtler D, Loeffelbein F, Stiller B, Langer M, Arnold R. Aortic flow patterns in patients with Marfan syndrome assessed by flow-sensitive four-dimensional MRI. Journal of magnetic resonance imaging : JMRI. 2012;35(3):594-600. 
27. van der Palen RL, Barker AJ, Bollache E, Garcia J, Rose MJ, van Ooij P, Young LT, Roest AA, Markl M, Robinson JD, Rigsby CK. Altered aortic 3D hemodynamics and geometry in pediatric Marfan syndrome patients. Journal of cardiovascular magnetic resonance : official journal of the Society for Cardiovascular Magnetic Resonance. 2017;19(1):30.

28. Geiger J, Hirtler D, Gottfried K, Rahman O, Bollache E, Barker AJ, Markl M, Stiller B. Longitudinal Evaluation of Aortic Hemodynamics in Marfan Syndrome: New Insights from a 4D Flow Cardiovascular Magnetic Resonance Multi-Year Follow-Up Study. Journal of cardiovascular magnetic resonance : official journal of the Society for Cardiovascular Magnetic Resonance. 2017;19(1):33.

29. Leidenberger T, Gordon Y, Farag M, Delles M, Fava Sanches A, Fink MA, Kallenbach K, Kauczor HU, Rengier F. Imaging-Based 4D Aortic Pressure Mapping in Marfan Syndrome Patients: A Matched Case-Control Study. The Annals of thoracic surgery. 2020;109(5):1434-40.

30. Marshall LM, Carlson EJ, O'Malley J, Snyder CK, Charbonneau NL, Hayflick SJ, Coselli JS, Lemaire SA, Sakai LY. Thoracic aortic aneurysm frequency and dissection are associated with fibrillin-1 fragment concentrations in circulation. Circulation research. 2013;113(10):1159-68.

31. Mordi IR, Forsythe RO, Gellatly C, Iskandar Z, McBride OM, Saratzis A, Chalmers R, Chin C, Bown MJ, Newby DE, Lang CC, Huang JTJ, Choy AM. Plasma Desmosine and Abdominal Aortic Aneurysm Disease. Journal of the American Heart Association. 2019;8(20):e013743.

32. Shinohara T, Suzuki K, Okada M, Shiigai M, Shimizu M, Maehara T, Ohsuzu F. Soluble elastin fragments in serum are elevated in acute aortic dissection. Arteriosclerosis, thrombosis, and vascular biology. 2003;23(10):1839-44.

33. Pilecki B, Holm AT, Schlosser A, Moeller JB, Wohl AP, Zuk AV, Heumuller SE, Wallis R, Moestrup SK, Sengle G, Holmskov U, Sorensen GL. Characterization of Microfibrillar-associated Protein 4 (MFAP4) as a Tropoelastin- and Fibrillin-binding Protein Involved in Elastic Fiber Formation. The Journal of biological chemistry. 2016;291(3):1103-14.

34. Pilop C, Aregger F, Gorman RC, Brunisholz R, Gerrits B, Schaffner T, Gorman JH, 3rd, Matyas G, Carrel T, Frey BM. Proteomic analysis in aortic media of patients with Marfan syndrome reveals increased activity of calpain 2 in aortic aneurysms. Circulation. 2009;120(11):983-91.

35. Yin X, Wanga S, Fellows AL, Barallobre-Barreiro J, Lu R, Davaapil H, Franken R, Fava M, Baig F, Skroblin P, Xing Q, Koolbergen DR, Groenink M, Zwinderman AH, Balm R, de Vries CJM, Mulder BJM, Viner R, Jahangiri M, Reinhardt DP, Sinha S, de Waard V, Mayr M. Glycoproteomic Analysis of the Aortic Extracellular Matrix in Marfan Patients. Arteriosclerosis, thrombosis, and vascular biology. 2019;39(9):1859-73.

36. Crosas-Molist E, Meirelles T, Lopez-Luque J, Serra-Peinado C, Selva J, Caja L, Gorbenko Del Blanco D, Uriarte JJ, Bertran E, Mendizabal Y, Hernandez V, Garcia-Calero C, Busnadiego O, Condom E, Toral D, Castella M, Forteza A, Navajas D, Sarri E, Rodriguez-Pascual F, Dietz HC, Fabregat I, Egea G. Vascular smooth muscle cell phenotypic changes in patients with Marfan syndrome. Arteriosclerosis, thrombosis, and vascular biology. 2015;35(4):960-72. 
37. Franken R, den Hartog AW, de Waard V, Engele L, Radonic T, Lutter R, Timmermans J, Scholte AJ, van den Berg MP, Zwinderman AH, Groenink M, Mulder BJ. Circulating transforming growth factor-beta as a prognostic biomarker in Marfan syndrome. International journal of cardiology. 2013;168(3):2441-6.

38. Davis MR, Arner E, Duffy CR, De Sousa PA, Dahlman I, Arner P, Summers KM. Expression of FBN1 during adipogenesis: Relevance to the lipodystrophy phenotype in Marfan syndrome and related conditions. Molecular genetics and metabolism. 2016;119(1-2):174-85.

39. Romere C, Duerrschmid C, Bournat J, Constable P, Jain M, Xia F, Saha PK, Del Solar M, Zhu B, York B, Sarkar P, Rendon DA, Gaber MW, LeMaire SA, Coselli JS, Milewicz DM, Sutton VR, Butte NF, Moore DD, Chopra AR. Asprosin, a Fasting-Induced Glucogenic Protein Hormone. Cell. 2016;165(3):566-79.

40. Durnin JV, Womersley J. Body fat assessed from total body density and its estimation from skinfold thickness: measurements on 481 men and women aged from 16 to 72 years. The British journal of nutrition. 1974;32(1):77-97.

41. Chen PY, Qin L, Li G, Malagon-Lopez J, Wang Z, Bergaya S, Gujja S, Caulk AW, Murtada SI, Zhang X, Zhuang ZW, Rao DA, Wang G, Tobiasova Z, Jiang B, Montgomery RR, Sun L, Sun H, Fisher EA, Gulcher JR, Fernandez-Hernando C, Humphrey JD, Tellides G, Chittenden TW, Simons M. Smooth Muscle Cell Reprogramming in Aortic Aneurysms. Cell stem cell. 2020;26(4):542-57.e11.

42. Pedroza AJ, Tashima Y, Shad R, Cheng P, Wirka R, Churovich S, Nakamura K, Yokoyama N, Cui JZ, losef C, Hiesinger W, Quertermous T, Fischbein MP. Single-Cell Transcriptomic Profiling of Vascular Smooth Muscle Cell Phenotype Modulation in Marfan Syndrome Aortic Aneurysm. Arteriosclerosis, thrombosis, and vascular biology. 2020:Atvbaha120314670.

43. Granata A, Serrano F, Bernard WG, McNamara M, Low L, Sastry P, Sinha S. An iPSC-derived vascular model of Marfan syndrome identifies key mediators of smooth muscle cell death. Nature genetics. 2017;49(1):97-109.

44. Ware JE, Jr., Sherbourne CD. The MOS 36-item short-form health survey (SF-36). I. Conceptual framework and item selection. Medical care. 1992;30(6):473-83.

45. Gandek B, Ware JE, Aaronson NK, Apolone G, Bjorner JB, Brazier JE, Bullinger M, Kaasa S, Leplege A, Prieto L, Sullivan M. Cross-validation of item selection and scoring for the SF-12 Health Survey in nine countries: results from the IQOLA Project. International Quality of Life Assessment. Journal of clinical epidemiology. 1998;51(11):1171-8.

46. Zigmond AS, Snaith RP. The hospital anxiety and depression scale. Acta psychiatrica Scandinavica. 1983;67(6):361-70.

47. Spinhoven P, Ormel J, Sloekers PP, Kempen GI, Speckens AE, Van Hemert AM. A validation study of the Hospital Anxiety and Depression Scale (HADS) in different groups of Dutch subjects. Psychological medicine. 1997;27(2):363-70.

48. Bjelland I, Dahl AA, Haug TT, Neckelmann D. The validity of the Hospital Anxiety and Depression Scale. An updated literature review. Journal of psychosomatic research. 2002;52(2):69-77.

49. Vercoulen J. De checklist individuele spankracht (CIS). In: Alberts M, editor. 1994. 
50. Vercoulen JH, Swanink CM, Fennis JF, Galama JM, van der Meer JW, Bleijenberg G. Dimensional assessment of chronic fatigue syndrome. Journal of psychosomatic research. 1994;38(5):383-92.

51. Worm-Smeitink M, Gielissen M, Bloot L, van Laarhoven HWM, van Engelen BGM, van Riel $P$, Bleijenberg G, Nikolaus S, Knoop H. The assessment of fatigue: Psychometric qualities and norms for the Checklist individual strength. Journal of psychosomatic research. 2017;98:40-6.

\section{Figures}

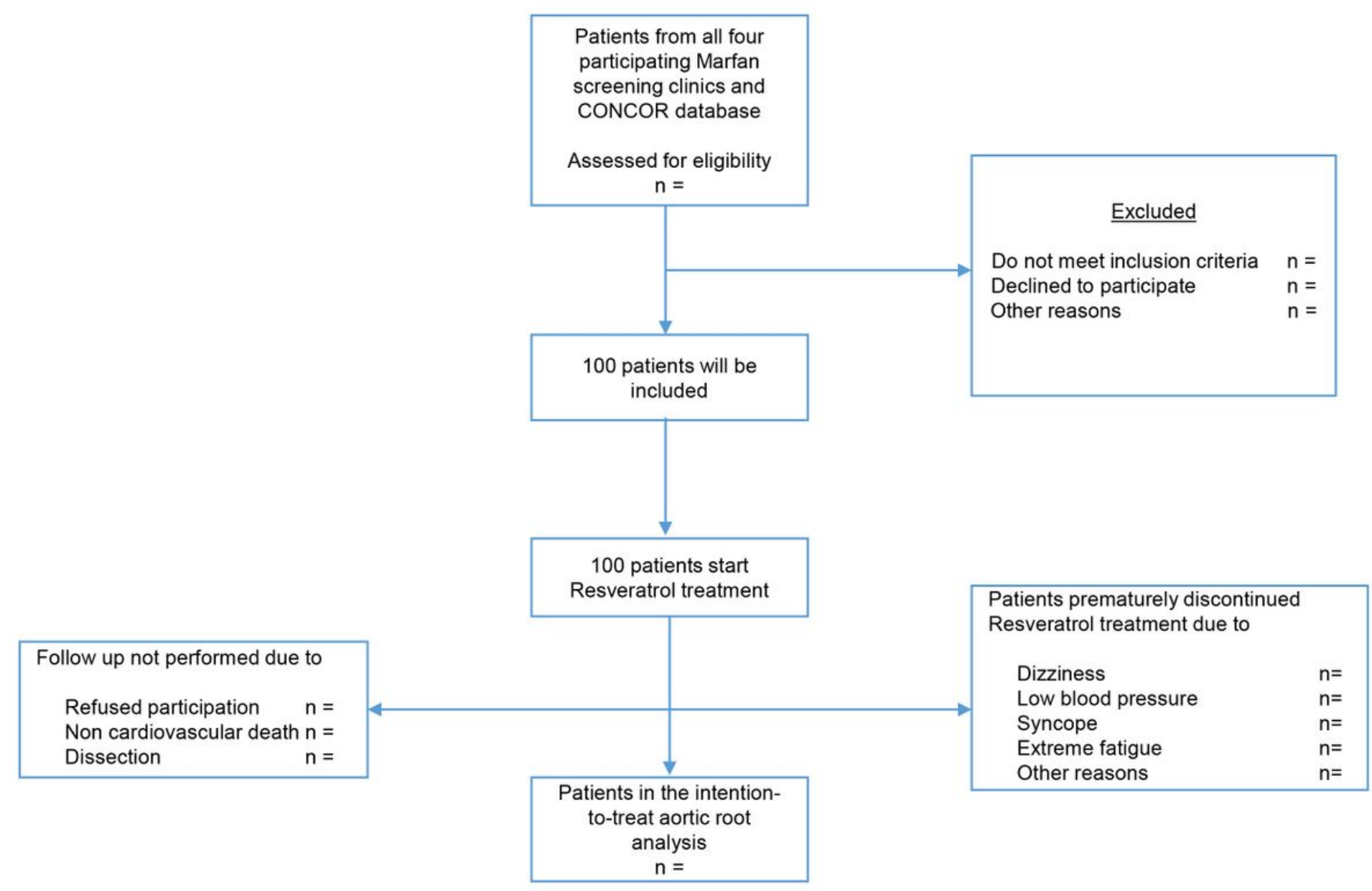

\section{Figure 1}

Study design of the RESVcue Marfan study. 


\begin{tabular}{|c|c|c|c|c|c|}
\hline \multirow[b]{3}{*}{ TIMEPOINT } & \multicolumn{5}{|c|}{ STUDY PERIOD } \\
\hline & \multirow{2}{*}{$\begin{array}{c}\text { Enrolment } \\
\text { Start }\end{array}$} & \multicolumn{3}{|c|}{ Follow-up } & \multirow{2}{*}{$\begin{array}{c}\text { Close-out } \\
1 \\
\text { year }\end{array}$} \\
\hline & & $\begin{array}{c}3 \\
\text { months }\end{array}$ & $\begin{array}{c}6 \\
\text { months }\end{array}$ & $\begin{array}{c}9 \\
\text { months }\end{array}$ & \\
\hline \multicolumn{6}{|l|}{ ENROLMENT: } \\
\hline \multirow{2}{*}{$\begin{array}{l}\text { Eligibility screen } \\
\text { Informed consent }\end{array}$} & $x$ & & & & \\
\hline & $X$ & & & & \\
\hline \multicolumn{6}{|l|}{ INTERVENTIONS: } \\
\hline \multicolumn{6}{|l|}{ Resveratrol } \\
\hline \multicolumn{6}{|l|}{ Treatment as usual } \\
\hline \multicolumn{6}{|l|}{ ASSESSMENTS: } \\
\hline \multirow{3}{*}{$\begin{array}{r}\text { Baseline characteristics } \\
\text { Physical examination } \\
\text { Blood analyses }\end{array}$} & $X$ & & & & $\mathrm{X}$ \\
\hline & X & & & & $x$ \\
\hline & $X$ & & & & $\mathrm{X}$ \\
\hline \multirow{2}{*}{ Skin biopsy } & $\mathrm{X}$ & & & & $x$ \\
\hline & $X$ & & & & $\mathrm{X}$ \\
\hline $\begin{array}{r}\text { Echocardiography } \\
\text { MRI }\end{array}$ & $\mathrm{X}$ & & & & $X$ \\
\hline \multicolumn{6}{|l|}{ Questionnaires } \\
\hline$S F-12$ & X & & & & $\mathrm{X}$ \\
\hline \multirow{2}{*}{ HADS } & $X$ & & & & $\mathrm{X}$ \\
\hline & $X$ & & & & $x$ \\
\hline $\begin{array}{r}\text { CIS } \\
\text { Telephone consultation }\end{array}$ & & $x$ & $\mathrm{X}$ & $\mathrm{X}$ & \\
\hline \multirow{2}{*}{ Well being } & & $x$ & $x$ & $\mathrm{X}$ & \\
\hline & & $\mathrm{X}$ & $X$ & $X$ & \\
\hline
\end{tabular}

\section{Figure 2}

Schedule of enrolment, intervention and assessment of the RESVcue Marfan study. 


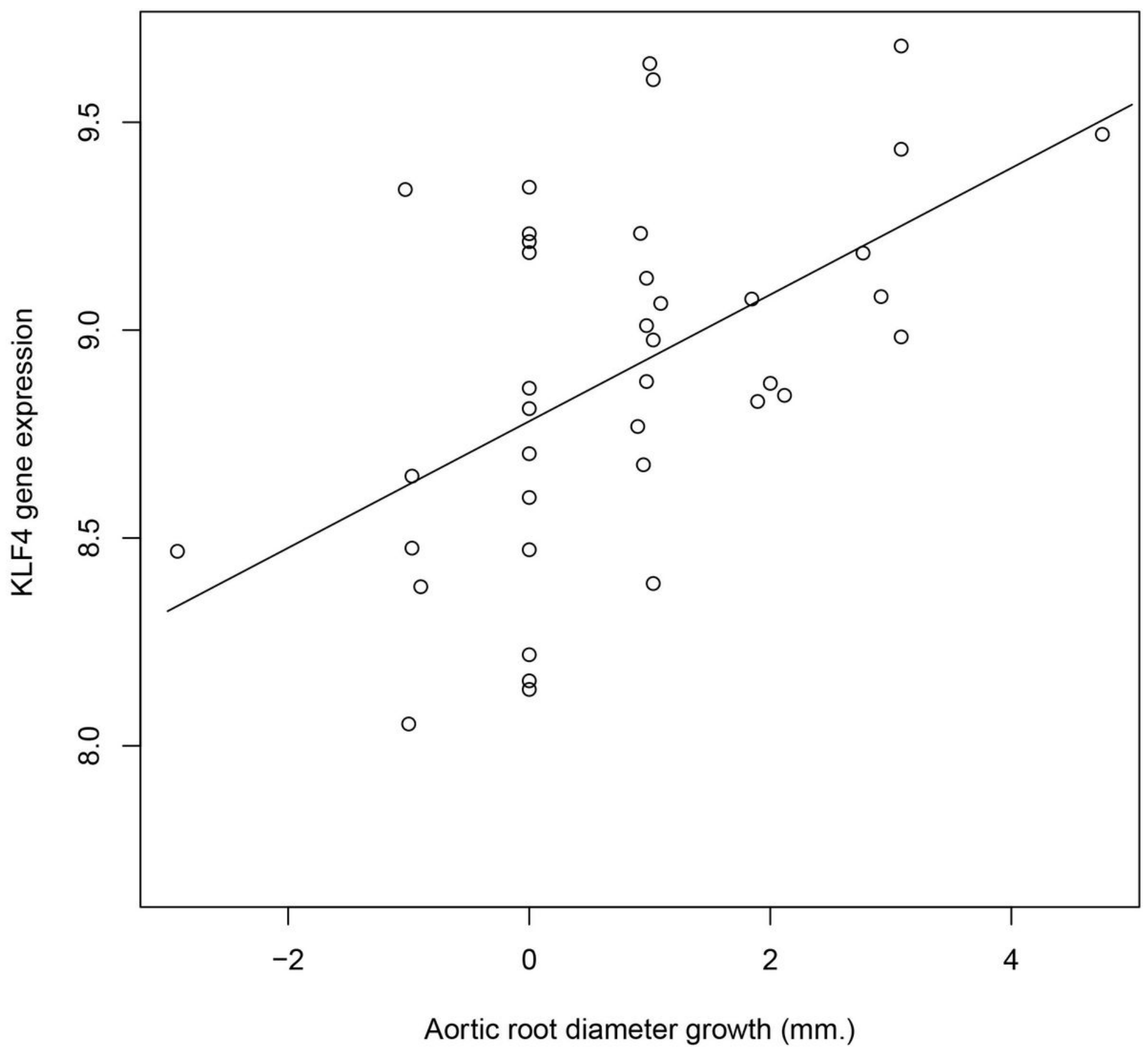

Figure 3

Association between KLF4 expression in skin samples of patients with MFS from the COMPARE cohort and aortic root diameter growth $(\mathrm{p}=0.00061)$.

\section{Supplementary Files}

This is a list of supplementary files associated with this preprint. Click to download.

- SPIRITChecklist18012021.docx

- InformedConsent18012021.pdf 